\title{
International Workshop on Process Intensification 2015 (IWPI2015): Towards Sustainable Process Technologies in the 21st Century (Canik Basari University, Samsun, Turkey, April 27-30, 2015)
}

DOI 10.1515/gps-2014-0076

\section{History and objectives of the International Workshop on Process Intensification (IWPI)}

The first three International Workshop on Process Intensification (IWPI) meetings were held in Japan, Kobe (2006), Tokyo (2008) and Fukuoka (2010) followed by the IWPI meeting in Korea (Seoul) in 2012. The next meeting, IWPI 2015, will be held in Turkey. The aim of IWPI is the promotion of Process Intensification as an emerging interdisciplinary technology with particular emphasis on science, engineering and technology development.

Process Intensification (PI) can be deemed to be the defining characteristic of the Chemical/Biochemical and Energy/Fuel technologies of the 21st century when clean and sustainable processes are essential to combat global warming and to mitigate the emerging food, energy and water shortages. PI-based technologies have no burden of 'economies of scale' making intensified chemical/biochemical plants sustainable even at a small scale, thus allowing the viability of local generation and consumption, as indeed recently demonstrated. Here, the ultimate aim is the establishment of an integrated intensified BioRefinery technology to replace the well established petrochemical refineries as well as chemical processing plants based on fossil fuel feedstock and centralized

*Corresponding authors: Galip Akay, Canik Basari University, Samsun, Turkey; and GAP Technologies Ltd, 1 Grosvenor Place, Level 8, London SW1X 7HJ, UK, e-mail: Galip.Akay1@gmail.com; and Ferhat Ozturk, Canik Basari University, Samsun, Turkey, e-mail: ferhatozturk@basari.edu.tr generation. However, a sustainable intensified production platform must be based on the integration of intensified unit operations. Furthermore, PI can also be applied on a large scale, to centralized and fossil fuel based energy generation, such as power plants and oil/petrochemical refineries or chemical plants, making them sustainable and greener. Based on the understanding of momentum, heat and mass transfer and their interactions within the intensified bio- or chemical reactors, it is also possible to challenge the efficiency and selectivity in long established production techniques in other disciplines, such as agriculture and environmental processes, providing more efficient alternatives.

\section{Key objectives of IWPI-2015}

In line with the general objectives of IWPI, this meeting (IWPI-2015) aims to create an interdisciplinary environment covering not only Chemical Engineering applications but also subjects which can both create inspiration to PI and also benefit from PI philosophy. These subjects include Agriculture, Biotechnology/Medicine, Chemistry, Energy Conversion and Environmental Processes, Materials Science, Modelling and Process Control. Research and development papers, either as a single intensified process or as Integrated Process Intensification applied to industrial production, are welcome.

Integrated Process Intensification (IPI) is particularly suitable for the development of Climate-Change Abatement Technologies (C-CATs). As the techno-economic characteristics of C-CATs are inherently present in IPI, IWPI-2015 will closely examine this new and important opportunity to deliver sustainable process technologies for the 21st Century. There will be a number of invited keynote lectures on some of these topics from industry and academia. Oral and/or poster contributions are 
welcome on the following topics which are only for guidance, but not exclusive.

\section{IWPI-2015 topics}

- Fundamentals and phenomenon based intensification

- Chemical technology applications

- Biology, biotechnology and in vitro medicine

- Energy and environment

- Climate change abatement technologies

- Applications of process intensification at a large scale

- Materials for process intensification

- Modelling and process control

- Integrated process intensification

\section{Invited keynote speakers} (confirmed)

- Prof Masahiko Abe, Tokyo Science University, Japan

- Dr Haoki Furukawa, Kaneka Corporation, Japan

- Prof Bulent Keskinler, Gebze Institute of Technology, Turkey

- Prof Spas Kolev, The University of Melbourne, Australia

- Prof Leslaw Mleczko, Bayer, Germany

- Mr Koos Overwater, Technip Benelux B.V., The Netherlands

- Prof Ken-ichiro Sotowa, Tukushima University, Japan

- Prof Esther Sulman, Tver Technical University, Russia
- Prof Da-Ming Wang, National Taiwan University, Taiwan

- $\quad$ Prof Yong Wang, Pacific Northwest National Laboratory, USA

- Dr Jie Wu, CSIRO Mineral Resources Flagship, Australia

\section{Venue}

Samsun is a historic city with a population of over half a million people on the north coast of Turkey. It is the provincial capital of Samsun Province and a major Black Sea port and home to two universities. It is easily accessible from Istanbul and Ankara by air.

\section{Abstract submission and journal publication}

Abstracts can be submitted online at the conference website: http://iwpi2015.basari.edu.tr/?callforpapers

Alternatively, abstracts can be submitted as an email attachment sent to the conference email address at: IWPI2015@basari.edu.tr

Invited papers will be submitted for publication in peer reviewed special edition journals.

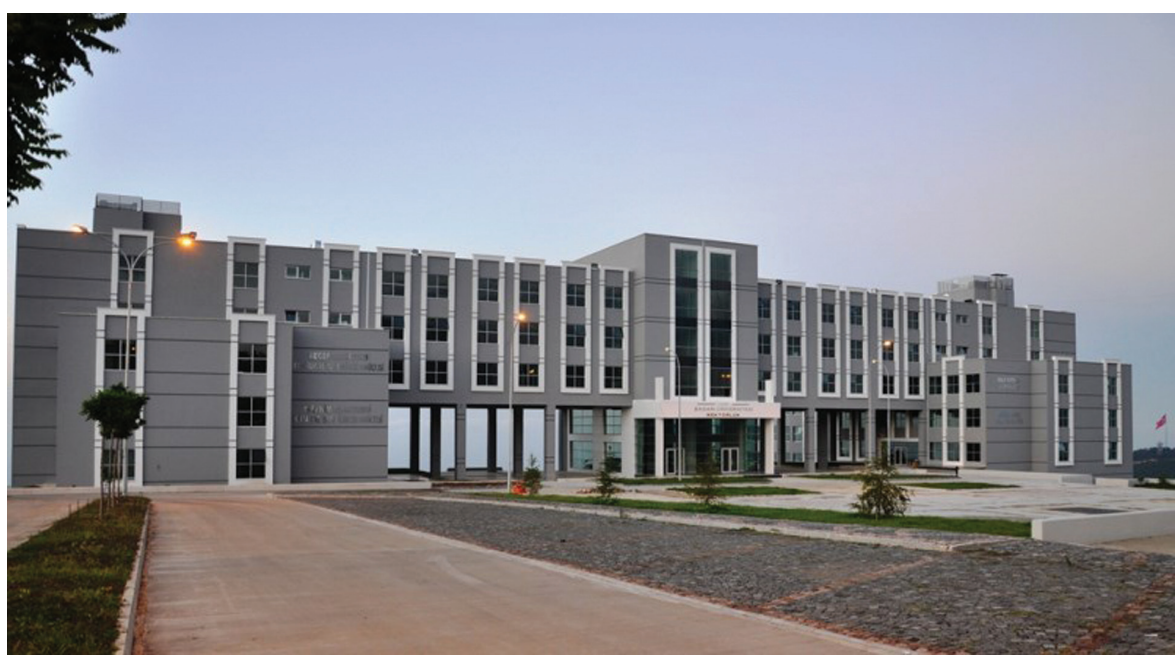

Canik Basari University 


\section{Important dates/deadlines}

Abstract submission: 2 February 2015

Confirmation of Acceptance: 16 February 2015

Submission of full manuscripts for peer review in journal publication: 14 September 2015

For further details visit http://iwpi2015.basari.edu.

$\operatorname{tr} /$ ?callforpapers

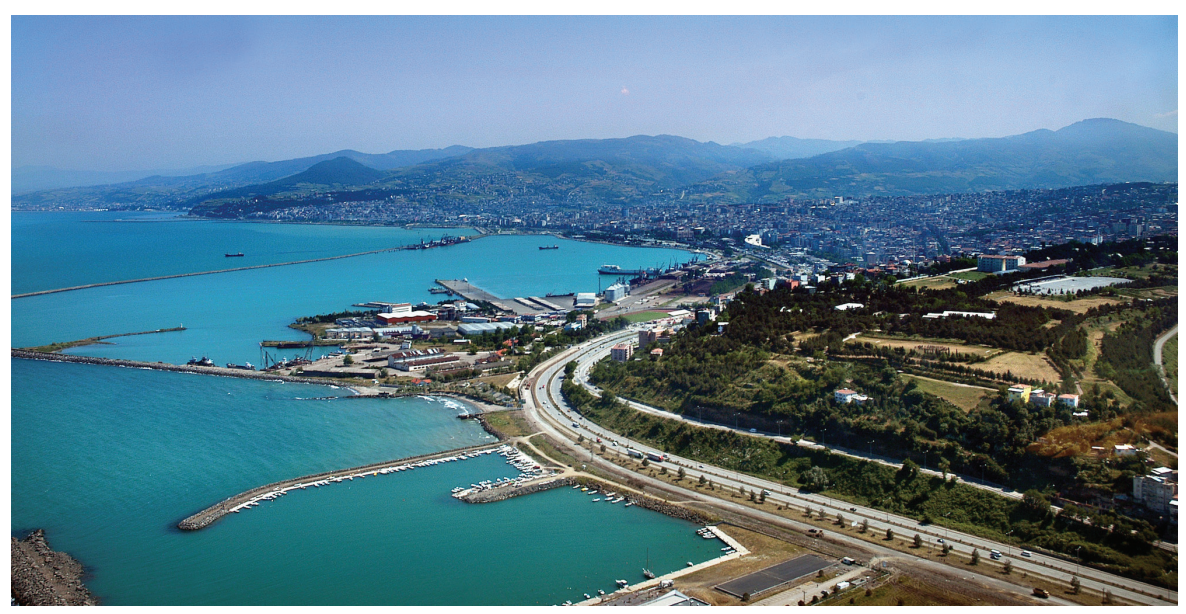

Samsun 